PPPL-3022

PPPL-3022

UC-420,427

NONLINEAR SATURATION OF-TOROIDAL ALFVÉN EIGENMODES VIA ION COMPTON SCATTERING

BY

T.S. HAHM AND L. CHEN

NOVEMBER 1994
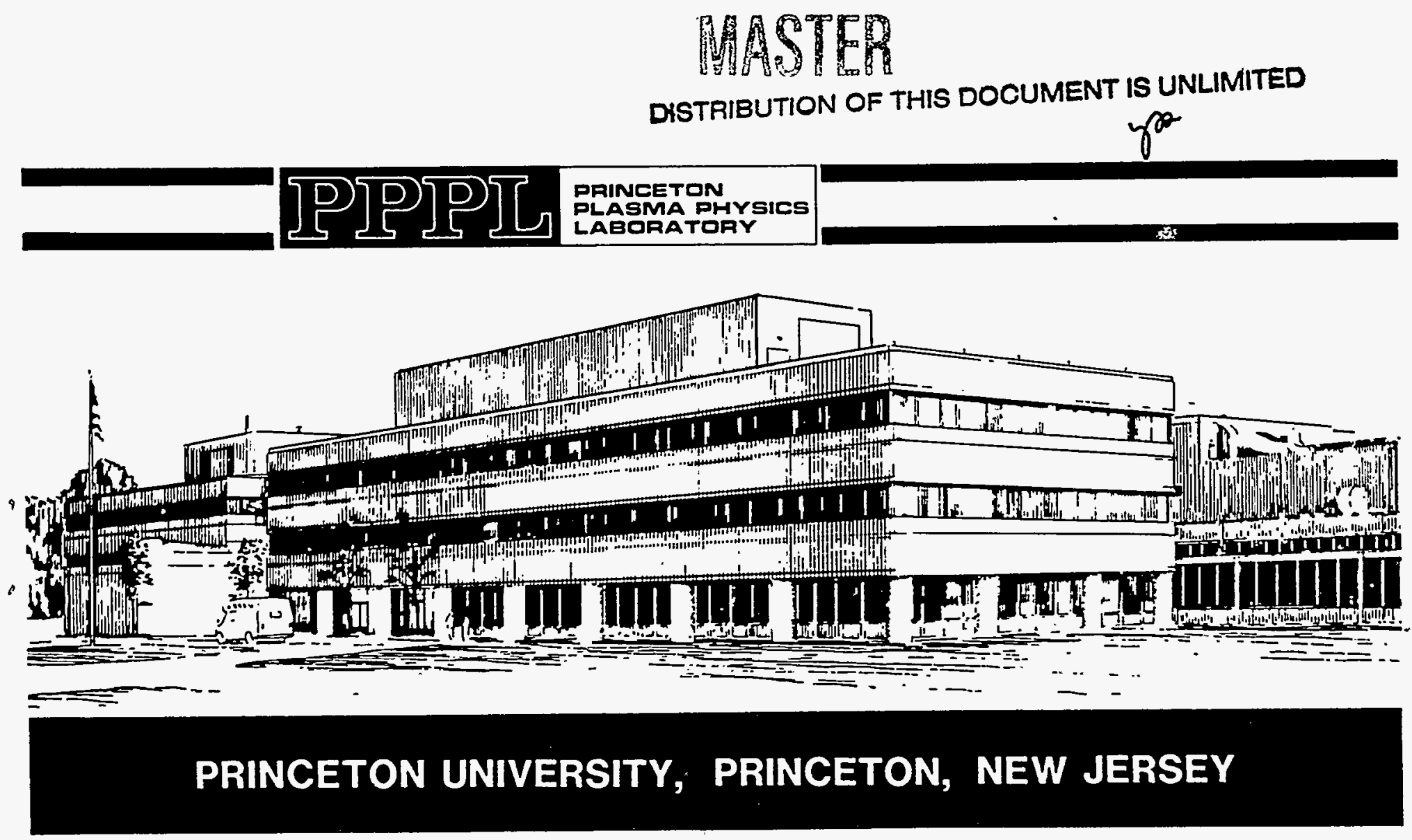


\section{NOTICE}

This report was prepared as an account of work sponsored by an agency of the United States Government. Neither the United States Government nor any agency thereof, nor any of their employees, makes any warranty, express or implied, or assumes any legal liability or responsibility for the accuracy, completeness, or usefulness of any information, apparatus, product, or process disclosed, or represents that its use would not infringe privately owned rights. Reference herein to any specific commercial produce, process, or service by trade name, trademark, manufacturer, or otherwise, does not necessarily constitute or imply its endorsement, recommendation, or favoring by the United States Government or any agency thereof. The views and opinions of authors expressed herein do not necessarily state or reflect those of the United States Government or any agency thereof.

\section{NOTICE}

This report has been reproduced from the best available copy. Available in paper copy and microfiche.

Number of pages in this report: 13

DOE and DOE contractors can obtain copies of this report from:

Office of Scientific and Technical Information P.O. Box 62

Oak Ridge, TN 37831;

(615) 576-8401.

This report is publicly available from the:

National Technical Information Service

Department of Commerce

5285 Port Royal Road

Springfield, Virginia 22161

(703) $487-4650$ 


\section{DISCLAIMER}

Portions of this document may be illegible in electronic image products. Images are produced from the best available original document. 


\title{
Nonlinear Saturation of Toroidal Alfvén Eigenmodes via Ion Compton Scattering
}

\author{
T.S. Hahm \\ Princeton University, Princeton Plasma Physics Laboratory, P.O. Box 451, Princeton, NJ 08543 \\ Liu Chen \\ Department of Physics, University of California, Irvine, California 92717.
}

The nonlinear interactions of high mode number Toroidal Alfvén Eigenmodes (TAE), mediated via Compton scattering off the bulk ions, are investigated. It is shown that nonlinear $J_{\perp} \times B_{\perp}$ ponderomotive force produced by TAE's interaction drives sound wave like density fluctuation with low phase velocity which can resonantly interact with the bulk ion parallel motion. Consequently, fluctuation energy of TAE's is transferred to lower frequency and eventually absorbed by linearly stable TAE's near the lower shear-Alfvén continuum, leading to nonlinear saturation. Explicit expression for the saturated magnetic amplitude is derived.

PACS Numbers: $52.35 . \mathrm{Mw}, 52.35 . \mathrm{Bj}, 52.25 . \mathrm{Gj}$ 
Since the importance of the toroidicity-induced Alfvén eigenmode (TAE) [1] in present and future generation tokamak devices has been indicated, significant progress has been made in experimental identification $[2-5]$ and detailed predictions on the linear stability $[6,7]$. High- $\mathrm{N}$ (toroidal mode number) TAE's have higher linear growth rates and it is important to know their amplitudes at nonlinear saturation and the implications on the ensuing alpha $(\alpha)$ particle loss. Previous studies [8-11] on the nonlinear interaction of high-N shear Alfvén fluctuations are based on a working paradigm of kinetic Alfvén wave (KAW). We note that TAE's are qualitatively different from KAW's in their mode structure and dispersion characteristics. Nonlinear behavior of TAE's, on the other hand, has been theoretically studied only for low- $\mathrm{N}$ modes in the context of single wave trapping, profile modification [12-14], and magnetohydrodynamic (MHD) mode coupling [15,16]. In this letter, we consider a different nonlinear mechanism which is relevant to high-N TAE's saturation. As wellknown, the linear coupling of different poloidal harmonics due to the toroidal magnetic field variation on a given flux surface induces the formation of a TAE. A TAE typically contains a few dominant poloidal harmonics and its eigenfrequency is most sensitive to the equilibrium parameters at the amplitude peak. Therefore, there exist many $(O(N q)$, here $q$ is the safety factor) high-N TAE modes with the same toroidal mode number, and they differ by their radial locations and eigenfrequencies. We investigate, as a candidate for the saturation mechanism, the nonlinear interactions among them mediated via Compton scattering off thermal ions. Specifically, we show that nonlinear $J_{\perp} \times B_{\perp}$ ponderomotive force produced by TAE's interaction drives sound-wave-like density fluctuation which in turn induces the spectral transfer of fluctuation energy toward lower-frequency TAE's. The fluctuation energy is eventually absorbed by linearly stable TAE's near the lower shear Alfvén continuum. The 
fluctuation level at nonlinear saturation is then predicted to be

$$
\left(\frac{\delta B_{r}}{B_{0}}\right)^{2} \simeq \frac{1}{4 \pi}\left(1+\frac{T_{e}}{T_{i}}\right)^{2} \epsilon^{4}\left(\frac{\bar{\gamma}_{L}}{\omega_{A}}\right)
$$

where $\epsilon \equiv 2\left(r_{o} / R_{o}+\Delta^{\prime}\right)$ is the effective local inverse aspect ratio which quantifies the strength of the toroidal coupling [17]. $\Delta^{\prime}$ is the radial derivative of the Shafranov shift, $\omega_{A}=v_{A} / 2 q R_{0}$, $v_{A}^{2}=B_{0}^{2} / 4 \pi \rho$, and $\bar{\gamma}_{L}$ is the spectrum average value of the linear growth rates (Eq. (16)).

We perform a third order nonlinear perturbation theory. To the first order, linear evolution of a test TAE (wave number $k$ ) is described by the ideal MHD equation which consists of the following frozen-in-flux constraint and vorticity equation:

$$
\frac{\partial}{\partial t} \psi_{k}^{(1)}=-\mathbf{n} \cdot \nabla \phi_{k}^{(1)}
$$

and

$$
\frac{\partial}{\partial t} \nabla_{\perp}^{2} \phi_{k}^{(1)}=-v_{A}^{2} \mathbf{n} \cdot \nabla \nabla_{\perp}^{2} \psi_{k}^{(1)}
$$

where $\phi_{k}$ and $\psi_{k}$ are the perturbed electrostatic potential and parallel vector potential respectively, and $\mathrm{n}=B_{0} / B_{0}$. In this work, we shall focus exclusively on the nonlinear interactions and refer the reader to the literature for details of the linear theory. With this approach in mind, no explicit expressions for the linear drive and damping will be given which, in any case, have little effects on the mode structure and the nonlinear interactions.

To the second order, the interaction of counter propagating components of two TAE's modes produces $\delta J_{\perp} \times \delta \boldsymbol{B}_{\perp} \cdot \mathbf{n}$ ponderomotive force which drives sound wave like density perturbation with low phase velocity. Here, it is crucial to recall that each poloidal harmonics of a given TAE has a different radially varying $k_{\|}$, although they share the same eigenfrequency. Each poloidal harmonics can propagate either parallel or anti-parallel to the magnetic field 
depending on the radial location. A particular combination of two TAE components which produces low phase velocity density perturbation is $\left(\omega_{\boldsymbol{k}}, N, m\right)$ and $\left(\omega_{\boldsymbol{k}^{\prime}}, N, m+1\right)$, because they have the opposite signs of $k_{\|}$(i.e., a back scattering) at the gap position. Here, $m$ is the poloidal mode number. The phase velocity of a beat wave is

$$
\frac{\omega^{\prime \prime}}{k_{\|}^{\prime \prime}}=\frac{\omega-\omega^{\prime}}{k_{\|}-k_{\|}^{\prime}} \simeq q R\left(\omega-\omega^{\prime}\right)
$$

at the gap position where the amplitude is significant. We also note that the radial overlap of the amplitude is most easily achieved for the interaction of TAE modes sharing the same toroidal mode number. The production of low frequency density fluctuation is described by the nonlinear ion drift kinetic equation [18]:

$$
\begin{array}{r}
\left(\frac{\partial}{\partial t}+v_{\|} \boldsymbol{b} \cdot \nabla\right) \delta f+\boldsymbol{v}_{E} \cdot \nabla f_{0}+\left(\frac{e}{M_{i}} E_{\|}-\boldsymbol{b} \cdot \frac{d}{d t} \boldsymbol{v}_{E}\right) \frac{\partial f_{0}}{\partial v_{\|}} \\
=\left(\boldsymbol{b} \cdot \frac{d}{d t} \boldsymbol{v}_{E}-\frac{e}{M_{i}} E_{\|}\right) \frac{\partial \delta f}{\partial v_{\|}}-\boldsymbol{v}_{E} \cdot \nabla \delta f
\end{array}
$$

where $\boldsymbol{v}_{E}=(\mathbf{n} \times \nabla \phi) / B_{0}, f_{0}$ and $\delta f$ are the equilibrium distribution function and the perturbed distribution function respectively, and $b \equiv \mathrm{n}+\delta B / B_{0}$ is the unit vector along the total magnetic field. Since a test TAE and the background TAE's (wave number $k^{\prime}$ ) are both high frequency $\left(\omega \gg \omega_{* e} \equiv\left(c T_{e} / e B_{0}\right) k_{\theta} / L_{n}\right)$ fluctuations, we have $\delta f_{\boldsymbol{k}} / f_{0} \ll e \phi_{\boldsymbol{k}} / T_{e}$, and $\delta f_{k^{\prime}} / f_{0} \ll e \phi_{k^{\prime}} / T_{e}$, and the nonlinear terms on the right hand side (RHS) are negligible. Then, the evolution equation for $\delta f_{\boldsymbol{k}^{\prime \prime}}$ (sound wave like beat wave) simplifies to

$$
\left(\frac{\partial}{\partial t}+v_{\|} \mathrm{n} \cdot \nabla\right) \delta f_{k^{\prime \prime}}=\left\{\left(\frac{\delta B}{B_{0}} \cdot \frac{\partial}{\partial t} \boldsymbol{v}_{E}\right)_{k^{\prime \prime}}+\frac{|e|}{M_{i}} \mathrm{n} \cdot \nabla \phi_{k^{\prime \prime}}\right\} \frac{\partial f_{0}}{\partial v_{\|}}
$$

where $k^{\prime \prime} \equiv k-k^{\prime}$. Since $\partial v_{E} / \partial t=v_{\text {pol }} \times B_{0} / M_{i}$, the first term on the RHS is proportional to $\left(\delta B_{\perp} \times \boldsymbol{v}_{\mathrm{pol}} \cdot \mathbf{n}\right)_{\boldsymbol{k}^{\prime \prime}}$. Noting that the perturbed perpendicular current is carried by the ion 
polarization drift, we can write this term as

$$
\frac{1}{n_{0}|e|}\left(\delta B_{\perp k} \times \delta J_{\perp k^{\prime}}^{*}+\delta B_{\perp k}^{*} \times \delta J_{\perp k}\right) \cdot \mathrm{n}
$$

which clearly indicates that it is the ponderomotive force produced by nonlinear interaction of two high frequency TAE' ( $k$ and $k^{\prime}$ ). This nonlinearity has been studied within MHD fluid description in a straight ambient $B_{0}[19,20]$. In Eq. (4), we have not kept the nonlinearity due to the $E \times B$ convection of the magnetic flux $\left(\boldsymbol{v}_{E} \cdot \nabla \psi=\delta \mathrm{B} \cdot \nabla \phi / B_{0}\right)$ assuming $\left(k_{\perp} \rho_{i}\right)^{2} \ll \omega / \Omega_{c i}$. In the opposite limit which corresponds to the short wavelength KAW's, that nonlinearity has been shown to be important [8]. Finally, $\omega^{\prime \prime} \ll \omega, \omega^{\prime}$ makes the induction field contribution $\left(\partial \psi_{k^{\prime \prime}} / \partial t\right)$ to the RHS of Eq. (4) insignificant. A standard Fourier decomposition and straightforward vector algebra lead to

$$
-i\left(\omega^{\prime \prime}-k_{\|}^{\prime \prime} v_{\|}\right) \delta f_{k^{\prime \prime}}^{(2)}=-\frac{i v_{\|}}{v_{T_{i}}^{2}}\left\{\frac{|e|}{M_{i}} k_{\|}^{\prime \prime} \phi_{k^{\prime \prime}}^{(2)}+\frac{1}{B_{0}^{2}}\left(k_{\|} \frac{\omega^{\prime}}{\omega}-k_{\|}^{\prime} \frac{\omega}{\omega^{\prime}}\right) \nabla \phi_{k^{\prime}}^{(1) *} \times \mathbf{n} \cdot \nabla \phi_{k}^{(1)} \times \mathbf{n}\right\} f_{0} .
$$

The corresponding density perturbation is

$$
\frac{\delta n_{\boldsymbol{k}^{\prime \prime}}^{(2)}}{n_{0}}=\chi_{i}\left(\boldsymbol{k}^{\prime \prime}\right)\left\{|e| \phi_{\boldsymbol{k}^{\prime \prime}}^{(2)}+\frac{M_{i}}{B_{0}^{2}} \frac{\left(k_{\|} \omega^{\prime} / \omega-k_{\|}^{\prime} \omega / \omega^{\prime}\right)}{k_{\|}} \nabla \phi_{\boldsymbol{k}^{\prime}}^{(1) *} \times \mathbf{n} \cdot \nabla \phi_{\boldsymbol{k}}^{(1)} \times \mathbf{n}\right\}
$$

where

$$
\chi_{i}\left(k^{\prime \prime}\right) \equiv \frac{1}{T_{i} n_{o}} \int d^{3} v \frac{k_{\|}^{\prime \prime} v_{\|}}{\omega^{\prime \prime}-k_{\|}^{\prime \prime} v_{\|}} f_{o i}
$$

is the ion linear susceptibility at $k^{\prime \prime}$. Since the electron nonlinearity is negligible due to smaller mass, the shielding potential $\phi_{k^{\prime \prime}}^{(2)}$ can be obtained via the following quasi-neutrality condition

$$
\frac{\delta n_{\boldsymbol{k}^{\prime \prime}}^{(2)}}{n_{0}}=\frac{\delta n_{e \cdot \boldsymbol{k}^{\prime \prime}}^{(2)}}{n_{0}}=-\chi_{e}\left(\boldsymbol{k}^{\prime \prime}\right)|e| \phi_{\boldsymbol{k}^{\prime \prime}}^{(2)}
$$

Here,

$$
\chi_{e}\left(\boldsymbol{k}^{\prime \prime}\right) \equiv \frac{1}{T_{e} n_{0}} \int d^{3} v \frac{k_{\|}^{\prime \prime} v_{\|}}{\omega^{\prime \prime}-k_{\|}^{\prime \prime} v_{\|}} f_{o e}
$$


is the electron linear susceptibility. The partial shielding contribution reduces the nonlinear density perturbation to, from Eq. (6),

$$
\frac{\delta n_{\boldsymbol{k}^{\prime \prime}}^{(2)}}{n_{0}}=\frac{\chi_{i} \chi_{e}}{\chi_{i}+\chi_{e}} \frac{M_{i}}{B_{0}^{2}} \frac{1}{k_{\|}^{\prime \prime}}\left(\frac{k_{\|} \omega^{\prime}}{\omega}-\frac{k_{\|}^{\prime} \omega}{\omega^{\prime}}\right) \nabla \phi_{\boldsymbol{k}^{\prime}}^{(1) *} \times \mathbf{n} \cdot \nabla \phi_{\boldsymbol{k}}^{(1)} \times \mathrm{n} .
$$

In this work, we shall concentrate on the resonant (imaginary) part of Eq. (7) which is responsible for the ion Compton scattering leading to the spectral transfer of fluctuation energy to lower frequency region. This restricts the applicability regime of our theory to low $\beta_{i}\left(\beta_{i}<\epsilon^{2}\right)$. For higher value of $\beta_{i}$, the nonlinear shift of real frequency caused by the real part of Eq. (7) must be considered. Noting

$$
\operatorname{Im} \chi_{e} \ll \operatorname{Im} \chi_{i} \equiv-\sqrt{\frac{\pi}{2}} \frac{\operatorname{sgn}\left(k_{\|}^{\prime \prime}\right)}{T_{i}} \frac{\omega^{\prime \prime} / k_{\|}^{\prime \prime}}{v_{T_{i}}} e^{-\left(\omega^{\prime \prime} / k_{\|}^{\prime \prime}\right)^{2} / 2 v_{T_{i}}^{2}}
$$

We then have, in Eq. (7),

$$
\operatorname{Im}\left(\frac{\chi_{e} \chi_{i}}{\chi_{e}+\chi_{i}}\right) \simeq \frac{\chi_{e}^{2}}{\left|\chi_{e}+\chi_{i}\right|^{2}} \operatorname{Im} \chi_{i}
$$

To the third order, the nonlinear evolution equation of a test TAE in the presence of the turbulent bath of other TAE's $\left(k^{\prime}\right)$ and the low frequency density perturbartion $\left(k^{\prime \prime}\right)$ is derived. Since the frozen-in-flux constraint is not affected by $\delta n_{k^{\prime \prime}}^{(2)}$, it suffices to study vorticity equation. Noting that the polarization current, $\delta \boldsymbol{J}_{\perp}=\left(1 / B_{0}\right) \mathbf{n} \times \rho\left(d \boldsymbol{v}_{E} / d t\right)$ depends on the ion number density, we obtain the following modified vorticity equation:

$$
v_{A}^{2} \mathrm{n} \cdot \nabla \nabla_{\perp}^{2} \psi_{k}+\frac{\partial}{\partial t} \nabla_{\perp}^{2} \psi_{k}+\sum_{\boldsymbol{k}^{\prime}} \nabla \cdot\left(\frac{\delta n_{\boldsymbol{k}^{\prime \prime}}^{(2)}}{n_{0}}\right) \frac{\partial}{\partial t} \nabla_{\perp} \phi_{\boldsymbol{k}^{\prime}}^{(1)}=0
$$

Here, we note that the nonlinearities due to field-line-bending $\nabla \psi_{k^{\prime}} \times \mathbf{n} \cdot \nabla \nabla_{\perp}^{2} \psi_{k}$ and $\mathrm{E} \times \mathrm{B}$ convection of vorticity $\left(\nabla \phi_{\boldsymbol{k}^{\prime}} \times \mathbf{n} \cdot \nabla \nabla_{\perp}^{2} \phi_{\boldsymbol{k}}\right)$ are subdominant to the last term [19]. Using the linear dispersion relation and the fact that $k_{r}^{\left({ }^{\prime}\right)} \gg k_{\theta}^{\left({ }^{\prime}\right)} \gg k_{\|}^{(\prime)}$, we can greatly 
simplify the nonlinear term of Eq. (8). By multiplying $\phi_{k}^{*}$ to $\partial(E q .(8)) \partial t$ and taking the imaginary part of the spatial average, we finally arrive at the following wave-kinetic equation for $I_{k} \equiv<\left|\nabla_{\perp} \phi_{k}\right|^{2}>$,

$$
\frac{\partial}{\partial t} I_{k}=\gamma_{L}(k) I_{k}-\sum_{k^{\prime}} M_{k, k^{\prime}} I_{k^{\prime}} I_{k}
$$

where

$$
M_{k, k^{\prime}} \equiv \frac{\omega^{\prime}}{2} \frac{\chi_{e}^{2} \operatorname{Im} \chi_{i}}{\left|\chi_{i}+\chi_{e}\right|^{2}} \frac{M_{i}}{B_{0}^{2}}
$$

At nonlinear saturation, the RHS must vanish. The mode summation over various nonlinear interaction channels can be approximated by an integral (the continuum approximation), if there exist many TAE's within the strong nonlinear interaction range $v_{T i} / q R \sim \beta_{i}^{1 / 2} \omega_{A}$. Since eigenfrequencies of TAE's separated by $\Delta r$ differ by $\omega_{A} / L_{A} \Delta r\left(L_{A}^{-1}=\left|\partial \ln \omega_{A} / \partial r\right|\right)$, the adjacent TAE's frequency difference is given by $\Delta \omega \simeq r_{0} \omega_{A} /\left(N q \hat{s} L_{A}\right)$, ( $\hat{s}$ is the magnetic shear). Therefore, the continuum approximation is justified for $\beta_{i}^{1 / 2} \gg 1 / N q \hat{s}$, taking $L_{A} \sim r_{0}$. Now, denoting TAE's with their eigenfrequencies, the nonlinear saturation condition becomes

$$
\gamma_{L}(\omega)=\int d \omega^{\prime} M_{\omega, \omega^{\prime}} I\left(\omega^{\prime}\right)
$$

where $\Sigma_{\boldsymbol{k}^{\prime}} I_{\boldsymbol{k}^{\prime}} \delta\left(\omega^{\prime}-\omega_{\boldsymbol{k}^{\prime}}\right)$ has been replaced by its continuum version $I\left(\omega^{\prime}\right)$.

Noting that $\left(k_{\|} \omega^{\prime} / \omega\right)-\left(k_{\|}^{\prime} \omega / \omega^{\prime}\right) \simeq k_{\|}^{\prime \prime}$, at the gap position $\left(k_{\|}=-k_{\|}^{\prime} \simeq 1 / 2 q R,\left|\omega-\omega^{\prime}\right| \lesssim\right.$ $\left.\left(r_{0} / R\right) \omega\right)$, we can write $M_{\omega, \omega^{\prime}}=\omega^{\prime} V\left(\omega^{\prime \prime}\right)$, where $V\left(\omega^{\prime \prime}\right) \equiv\left(M_{i} / 2 B_{0}^{2}\right) \chi_{e}^{2} \operatorname{Im} \chi_{i} /\left|\chi_{i}+\chi_{e}\right|$. Then, Eq. (10) can be converted to a differential equation if $\epsilon>\beta_{i}^{1 / 2}$, because the kernel $V\left(\omega^{\prime \prime}\right)$ varies faster than $\omega^{\prime} I\left(\omega^{\prime}\right)$ as a function of $\omega^{\prime}$. Using $\omega^{\prime} I\left(\omega^{\prime}\right) \simeq \omega I(\omega)-\omega^{\prime \prime} \partial(\omega I) / \partial \omega$, we obtain 


$$
\gamma_{L}(\omega)=\int d \omega^{\prime} V\left(\omega^{\prime \prime}\right)\left\{\omega I-\omega^{\prime \prime} \partial(\omega I) / \partial \omega\right\}
$$

The higher frequency modes tend to be TAE's excited near the plasma center (recall that $\omega_{A}=v_{A} / 2 q R_{0}, q(r)$ is typically an increasing function of $r$ ) where the hot particle pressure gradient peaks, they are more unstable. The lower frequency TAE's tend to be in a region where the hot particle drive is weaker. Furthermore, if a TAE frequency is close enough to the lower continuum, TAE is linearly stable due to strong continuum damping $[21,22]$. With this in mind, we can specify the integral limits of Eq. (11). The upper limit is given by $\omega_{M}$, the highest frequency of linearly unstable TAE's, and the lower limit is given by $\omega_{1}$, the lowest frequency with $I(\omega) \geq 0$. We note that $\omega_{1}$ corresponds to a linearly stable TAE because the downward spectral transfer due to ion Compton scattering can nonlinearly excite a linearly stable mode. Since both $\omega_{m}$ and $\omega_{1}$ are within a gap, $\omega_{M}-\omega_{1} \lesssim \epsilon \omega_{A}$. Changing the integration variable to $\omega^{\prime \prime}$, we obtain

$$
\gamma_{L}(\omega)=U_{0}(\omega) \omega I(\omega)-U_{1}(\omega) \frac{\partial}{\partial \omega}\{\omega I(\omega)\}
$$

where $U_{0}(\omega) \equiv \int_{\omega-\omega_{M}}^{\omega-\omega_{1}} d \omega^{\prime \prime} V\left(\omega^{\prime \prime}\right)$ and $U_{1}(\omega) \equiv \int_{\omega-\omega_{M}}^{\omega-\omega_{1}} d \omega^{\prime \prime} \omega^{\prime \prime} V\left(\omega^{\prime \prime}\right)$

Although it is possible to write the formal solution of Eq. (12) in terms of integrals of the error function, we simply present a more illuminating approximate solution. For $\omega-\omega_{1}$, $\omega_{M}-\omega \gtrsim v_{T_{i}} / q R, U_{0}(\omega)$ becomes exponentially small because $V\left(\omega^{\prime \prime}\right)$ is an odd function. Then, approximating $U_{1}(\omega)$ by

$$
\bar{U}_{1} \equiv \int_{-\infty}^{\infty} d \omega^{\prime \prime} \omega^{\prime \prime} V\left(\omega^{\prime \prime}\right)=\frac{\pi}{2} \frac{1}{\left\{1+\left(T_{e} / T_{i}\right)\right\}^{2}} \frac{1}{B_{0}^{2}} \frac{1}{(q R)^{2}}
$$

we can integrate Eq. (12) to obtain

$$
I(\omega)=\frac{1}{\omega}\left\{\omega_{M} I\left(\omega_{M}\right)+\frac{1}{\bar{U}_{1}} \int_{\omega}^{\omega_{M}} d \omega \gamma_{L}(\omega)\right\}
$$


Now let us estimate $I\left(\omega_{M}\right)$. For $\omega$ very close to $\omega_{M}\left(\omega_{M}-\omega \ll v_{T i} / q R\right)$,

$$
U_{1}(\omega) \simeq \int_{\omega-\omega_{M}}^{\infty} d \omega^{\prime \prime} V\left(\omega^{\prime \prime}\right) \omega^{\prime \prime}=O\left(\frac{\left(\omega_{M}-\omega\right)^{2}}{v_{T i}^{2}(q R)^{2}}\right) \bar{U}_{1}
$$

Thus, the first term on the right hand side of Eq. (12) is larger than the second term. Using

$$
U_{0} \simeq \bar{U}_{0} \equiv \int_{0}^{\infty} d \omega^{\prime \prime} V\left(\omega^{\prime \prime}\right)=\frac{1}{2} \sqrt{\frac{\pi}{2}} \frac{1}{\left(1+T_{e} / T_{i}\right)^{2} B_{0}^{2} v_{T i} q R}
$$

We obtain $I\left(\omega_{M}\right) \simeq \gamma_{L}\left(\omega_{M}\right) / \omega_{M} \bar{U}_{0}$ from Eq. (13). Then Eq. (13) can be written as

$$
I(\omega)=\frac{1}{\omega}\left[\frac{\gamma_{L}\left(\omega_{M}\right)}{\bar{U}_{0}}+\frac{1}{\bar{U}_{1}} \int_{\omega}^{\omega_{M}} d \omega \gamma_{L}(\omega)\right]
$$

As a consequence of the ion Compton scattering induced downward spectral transfer, the spectral intensity peaks at a frequency lower than that with maximum linear growth rate. Integrating the intensity over the fluctuation population zone, we obtain

$$
\int_{\omega_{1}}^{\omega_{M}} d \omega I(\omega)=\frac{\gamma_{L}\left(\omega_{M}\right)}{\bar{U}_{0}} \ln \left(\frac{\omega_{M}}{\omega_{1}}\right)+\frac{1}{\bar{U}_{1}} \int_{\omega_{1}}^{\omega_{M}} d \omega \gamma_{L}(\omega) \ln \left(\frac{\omega}{\omega_{1}}\right)
$$

Since $\bar{U}_{0}\left(\omega_{M}-\omega_{1}\right) / \bar{U}_{1}=O\left(\epsilon / \beta_{i}^{1 / 2}\right)$, we keep only the second term of Eq. (15). The corresponding magnetic fluctuation level at nonlinear saturation, which can be obtained by using the frozen-in-flux constraint, then becomes

$$
\left(\frac{\delta B_{\tau}}{B_{0}}\right)^{2} \simeq\left(\frac{k_{\theta}}{k_{\tau}}\right)^{2}\left(1+\frac{T_{e}}{T_{i}}\right)^{2} \frac{1}{2 \pi \omega_{A}^{2}} \int_{\omega_{1}}^{\omega_{M}} d \omega \gamma_{L}(\omega) \ln \left(\frac{\omega}{\omega_{1}}\right)
$$

For a rough estimation, we take $\gamma_{L}(\omega) \simeq \bar{\gamma}_{L}$, and expand the final expression in $\epsilon_{\text {eff }} \equiv$ $1-\omega_{1} / \omega_{M}$, to get

$$
\left(\frac{\delta B_{r}}{B_{0}}\right)^{2} \simeq \frac{1}{4 \pi}\left(1+\frac{T_{e}}{T_{i}}\right)^{2}\left(\frac{\bar{\gamma}_{L}}{\omega_{A}}\right) \epsilon^{2} \epsilon_{\mathrm{eff}}^{2}
$$

where $\left(k_{\theta} / k_{r}\right)^{2}=\epsilon^{2}$ has been used. For $\overline{\gamma_{L}} / \omega_{A} \lesssim 10^{-2}, \epsilon_{\text {eff }} \simeq \epsilon \sim 10^{-1}$, and $T_{e} / T_{i} \lesssim 1$, Eq. (17) yields $\delta B_{r} / B_{0} \lesssim 10^{-3}$. 
Since $\epsilon_{e f f} \lesssim \epsilon$, the saturation level is a strong $\left(\sim \epsilon^{4}\right)$ function of the inverse aspect ratio, and independent of $\beta_{i}$. The strong $\epsilon$ dependence originates from the radial localization of each poloidal component of TAE $\left(k_{\tau} \simeq k_{\theta} / \epsilon\right)$, and the proportionality of the fluctuation population range $\left(\omega_{M}-\omega_{1}\right)$ to $\epsilon$. The $\beta_{i}$-scaling which appears in Compton scattering cross-section $\left(\sim \operatorname{Im} \chi_{i}\right)$ for each pair $\left(k, k^{\prime}\right)$ of back scattering goes away after the mode summation because the nonlinear interaction range is given by $\left|\omega-\omega^{\prime}\right| \lesssim v_{T i} / q R$. As a result, the effective "convective velocity" $\bar{U}_{1}$ in $\omega$-space (see Eq. (13), and the saturation level is independent of $\beta_{i}$ in the low $\beta_{i}$ regime $\left(\beta_{i}<\epsilon^{2}\right)$ considered in this work. Finally, the temperature ratio appears due to the partial shielding by $\phi_{k^{\prime \prime}}^{(2)}$.

\section{ACKNOWLEDGEMENT}

Useful discussions with C.Z. Cheng, G.Y. Fu, E.J. Valeo, and F. Zonca are gratefully acknowledged. This work was supported by the U.S. Department of Energy Contract No. DE-AC02-76-CHO3073 and the U.S. Department of Energy Grant DE-FG03-94ER54271.

[1] C.Z. Cheng, L. Chen, and M.S. Chance, Ann. Phys. NY 161, 21 (1984).

[2] K.L. Wong, et al., Phys. Rev. Lett. 66, 1874 (1991).

[3] W.W. Heidbrink, et al., Nucl. Fusion 31, 1635 (1991).

[4] R.D. Durst, et al., Phys. Fluids 4, 3707 (1992).

[5] E.J. Strait, et al., Nucl. Fusion 33, 1849 (1993).

[6] C.Z. Cheng et al., in Proceedings of the 14th International Conference on Plasma Physics and Controlled Nuclear Fusion Research, (IAEA, Vienna, 1993), Vol. 2, p. 51. 
[7] M.S. Chu et al., in Proceedings of the 14th International Conference on Plasma Physics and Controlled Nuclear Fusion Research, (IAEA, Vienna, 1993), Vol. 1, p. 855.

[8] A. Hasegawa and L. Chen, Phys. Fluids 19, 1924 (1976).

[9] E.A. Frieman and L. Chen, Phys. Fluids 25, 502 (1982).

[10] H. Biglari and P.H. Diamond, Phys. Fluids B 4, 3009 (1992).

[11] F.Y. Gang, D.J. Sigmar, and J-N. LeBoeuf, Phys. Lett. A 6517 (1992); F.Y Gang, Phys. Fluids B 4, 3152 (1992).

[12] H.L. Berk and B.N. Breizman, Phys. Fluids B 2, 2246 (1990).

[13] Y. Wu and R.B. White, Phys. Plasmas, 1, 2733 (1994).

[14] G.Y. Fu and W. Park, Bull. Am. Soc. 38, 945 (1993).

[15] G. Vlad et al., in Theory of Fusion Plasmas, edited by E. Sidoni and J. Vaclavik (Editrice Compositori, Bologna, 1992), pp. 361.

[16] D.A. Spong, B.A. Carreras, and C.L. Hedrick, Phys. Plasmas 1, 1503 (1994).

[17] F. Zonca and L. Chen, Phys. Fluids B 53668 (1993).

[18] R.M. Kulsrud, in Basic Plasma Physics, edited by A.A. Galeev and R.N. Sudan (NorthHolland, Amsterdam, 1983), Vol. I, pp. 115-146.

[19] R.Z. Sagdeev and A.A. Galeev, Nonlinear Plasma Theory, edited by T.M. O'Neill and D.L. Book (Bejamin, New York, 1969).

[20] R.M. Kulsrud, in Important Advances in Twentieth Century Astronomy (Anniversary volume for Bengt Stromgren), (Copenhagen University Observatory, Copenhagen, 1978), pp. 317-325.

[21] F. Zonca and L. Chen, Phys. Rev. Lett. 68, 592 (1992).

[22] M.N. Rosenbluth, et al., Phys. Rev. Lett. 68, 596 (1992). 
Dr. F. Paoloni, Univ. of Wollongong, AUSTRALIA

Prof. R.C. Cross, Univ. of Sydney, AUSTRALIA

Plasma Research Lab., Australian Nat. Univ., AUSTRALIA

Prof. I.R. Jones, Flinders Univ, AUSTRALIA

Prof. F. Cap, Inst. for Theoretical Physics, AUSTRIA

Prot. M. Heindler, Institut fur Theoretische Physik, AUSTRIA

Prof. M. Goossens, Astronomisch Instituut, BELGIUM

Ecole Royale Militaire, Lab. de Phy. Plasmas, BELGIUM

Commission-European, DG. XII-Fusion Prog., BELGIUM

Prot. R. Bouciqué, Rijksuniversiteit Gent, BELGIUM

Dr. P.H. Sakanaka, Instituto Fisica, BRAZIL

Prof. Dr. I.C. Nascimento, Instituto Fisica, Sao Paulo, BRAZIL Instituto Nacional De Pesquisas Espaciais-INPE, BRAZIL

Documents Office, Atomic Energy of Canada Lid., CANADA

Ms. M. Morin, CCFWTokamak de Varennes, CANADA

Dr. M.P. Bachynski, MPB Technologies, Inc., CANADA

Dr. H.M. Skarsgard, Univ. of Saskatchewan, CANADA

Prof. J. Teichmann, Univ. of Montreal, CANADA

Prof. S.R. Sreenivasan, Univ. of Calgary, CANADA

Prof. R. Marchand, INRS-Energie et Materiaux, CANADA

Dr. R. Bolton, Centre canadien de fusion magnétique, CANADA

Dr. C.R. James,, Univ. of Alberta, CANADA

Dr. P. Lukác, Komenského Universzita, CZECHO-SLOVAKIA

The Librarian, Culham Laboratory, ENGLAND

Library, R61, Rutherford Appleton Laboratory, ENGLAND

Mrs. S.A. Hutchinson, JET Library, ENGLAND

Dr. S.C. Sharma, Univ. of South Pacific. FIJI ISLANDS

P. Măhönen, Univ. of Helsinki, FINLAND

Prof. M.N. Bussac, Ecole Polytechnique, FRANCE

C. Mouttet, Lab. de Physique des Milieux lonisés, FRANCE

J. Radet, CEN/CADARACHE - Bat 506, FRANCE

Prof. E. Economou, Univ. of Crete, GREECE

Ms. C. Rinni, Univ. of loannina, GREECE

Preprint Library, Hungarian Academy of Sci., HUNGARY

Dr. B. DasGupta, Saha Inst. of Nuclear Physics, INDIA

Dr. P. Kaw, Inst. for Plasma Research, INDIA

Dr. P. Rosenau, Israel Inst. of Technology, ISRAEL

Librarian, International Center for Theo Physics, ITALY

Miss C. De Palo, Associazione EURATOM-ENEA, ITALY

Dr. G. Grosso, Istitu to di Fisica del Plasma, ITALY

Prol. G. Rostangni, Istituto Gas lonizzati Del Cnr, ITALY
Dr. H. Yamato, Toshiba Res \& Devel Center, JAPAN

Prof. I. Kawakami, Hiroshima Univ., JAPAN

Prof. K. Nishikawa, Hiroshima Univ., JAPAN

Librarian, Naka Fusion Research Establishment, JAERI, JAPAN

Director, Japan Atomic Energy Research Inst., JAPAN

Prof. S. Itoh, Kyushu Univ., JAPAN

Research Info. Ctr., National Instit. for Fusion Science, JAPAN

Prof. S. Tanaka, Kyoto Univ., JAPAN

Library, Kyoto Univ., JAPAN

Prof. N. Inoue, Univ. of Tokyo, JAPAN

Secretary, Plasma Section, Electrotechnical Lab., JAPAN

Dr. O. Mitarai, Kumamoto Inst. of Technology, JAPAN

Dr. G.S. Lee, Korea Basic Sci. Ctr., KOREA

J. Hyeon-Sook, Korea Atomic Energy Research Inst., KOREA

D.l. Choi, The Korea Adv. Inst. of Sci. \& Tech., KOREA

Prof. B.S. Liley, Univ. of Waikato, NEW ZEALAND

Inst of Physics, Chinese Acad Sci PEOPLE'S REP. OF CHINA

Library, Inst. of Plasma Physics, PEOPLE'S REP. OF CHINA

Tsinghua Univ. Library, PEOPLE'S REPUBLIC OF CHINA

Z. Li, S.W. Inst Physics, PEOPLE'S REPUBLIC OF CHINA

Prof. J.A.C. Cabral, Instituto Superior Tecnico, PORTUGAL

Prof. M.A. Hellberg, Univ. of Natal, S. AFRICA

Prof. D.E. Kim, Pohang Inst. of Sci. \& Tech., SO. KOREA

Prot. C.I.E.M.A.T. Fusion Division Library, SPAIN

Dr. L. Stenflo, Univ. of UMEA, SWEDEN

Library, Royal Inst. of Technology, SWEDEN

Prof. H. Wilhelmson, Chalmers Univ. of Tech., SWEDEN

Centre Phys. Des Plasmas, Ecole Polytech, SWITZERLAND

Bibliotheek, Inst. Voor Plasma-Fysica, THE NETHERLANDS

Asst. Prof. Dr. S. Cakir, Middle East Tech. Univ., TURKEY

Dr. V.A. Glukhikh,Sci. Res. Inst. Electrophys.I Apparatus, USSR

Dr. D.D. Ryutov, Siberian Branch of Academy of Sai., USSR

Dr. G.A. Eliseev, I.V. Kurchatov Inst., USSR

Librarian, The Ukr.SSR Academy of Sciences, USSR

Dr. L.M. Kovrizhnykh, Inst. of General Physics, USSR

Kernforschungsanlage GmbH, Zentralbibliothek, W. GERMANY

Bibliothek, Inst. Für Plasmaforschung, W. GERMANY

Prof. K. Schindler, Ruhr-Universitát Bochum, W. GERMANY

Dr. F. Wagner, (ASDEX), MaX-Planck-Institut, W. GERMANY

Librarian, Max-Planck-Institut, W. GERMANY 